\title{
O trabalho interdisciplinar na escola com projetos
}

\author{
Interdisciplinary work at school with projects \\ Trabajo interdisciplinario en la escuela con proyectos
}

Recebido: 08/10/2021 | Revisado: 15/10/2021 | Aceito: 27/01/2022 | Publicado: 29/01/2022

Lano Alves Costa

ORCID: https://orcid.org/0000-0002-7723-3377 Secretaria Municipal de Educação de Novo Gama, Brasil E-mail: lanopadre@hotmail.com

\begin{abstract}
Resumo
O sistema educacional atualmente, exige metodologias que gerem mudanças no ensino aprendizagem, fazendo o educando ser o protagonista da construção do próprio conhecimento. A Pedagogia de Projeto proposta como educação interdisciplinar, visa trabalhar competências e habilidades necessárias para transformação social. A ressignificação do ambiente escolar é necessária para inserir a escola nessa vivência contemporânea, a mudança de postura transforma a escola num lugar significativo de ensino aprendizagem, envolvendo a comunidade escolar dentro da sua realidade. A metodologia utilizada é de pesquisa documental e bibliográfica, de cunho qualitativo. A pedagogia de projeto apresentada neste artigo trabalha três momentos importantes: A etapa da problematização, do desenvolvimento do trabalho e a síntese, contribuindo efetivamente na formação do desenvolvimento social e cognitivo do educando. O educador é o mediador de todo o trabalho pedagógico e os educandos adquirem o conhecimento com a oportunidade de tornar a ação educativa mais significativa.
\end{abstract}

Palavras-chave: Pedagogia de projetos; Interdisciplinar; Educação.

\begin{abstract}
The educational system currently requires methodologies that generate changes in teaching and learning, making the student the protagonist of the construction of their own knowledge. The Project Pedagogy proposed as interdisciplinary education, aims to work skills and abilities necessary for social transformation. The redefinition of the school environment is necessary to insert the school in this contemporary experience, the change in attitude transforms the school into a significant place for teaching and learning, involving the school community within its reality. The methodology used is documentary and bibliographic research, with a qualitative nature. The project pedagogy presented in this article works on three important moments: The stage of problematization, work development and synthesis, effectively contributing to the formation of the student's social and cognitive development. The educator is the mediator of all pedagogical work and students acquire knowledge with the opportunity to make the educational action more meaningful.
\end{abstract}

Keywords: Project pedagogy; Interdisciplinary; Education.

\section{Resumen}

El sistema educativo requiere en la actualidad metodologías que generen cambios en la enseñanza y el aprendizaje, haciendo del alumno el protagonista de la construcción de su propio conocimiento. El Proyecto Pedagogía propuesto como educación interdisciplinar, tiene como objetivo trabajar las competencias y habilidades necesarias para la transformación social. La redefinición del entorno escolar es necesaria para insertar la escuela en esta experiencia contemporánea, el cambio de actitud convierte a la escuela en un lugar significativo para la enseñanza y el aprendizaje, involucrando a la comunidad escolar dentro de su realidad. La metodología utilizada es la investigación documental y bibliográfica, de carácter cualitativo. El proyecto de pedagogía presentado en este artículo trabaja en tres momentos importantes: La etapa de problematización, desarrollo y síntesis del trabajo, contribuyendo efectivamente a la formación del desarrollo social y cognitivo del alumno. El educador es el mediador de todo el trabajo pedagógico y los estudiantes adquieren conocimientos con la oportunidad de hacer más significativa la acción educativa.

Palabras clave: Pedagogía de proyectos; Interdisciplinario; Educación.

\section{Introdução}

Temos a educação como meio de transformação da sociedade, formando cidadãos críticos, conscientes, insubmissos, com capacidade de iniciativa, dentro dos quatro eixos da educação: aprender a aprender, aprender a ser, aprender a fazer e aprender a conhecer. 
Na perspectiva da Pedagogia de Projetos, o conhecimento produzido no âmbito escolar constitui-se a partir de conteúdos advindos das concepções dos educandos, dos temas cujos educandos revelam interesse e das questões contemporâneas: Os conhecimentos científicos não são vistos apenas como algo que precisa ser aprendido e sim enquanto instrumento para serem apropriados e atendidos, analisada objetivamente na compreensão da constituição de novos saberes e da vida.

"O 'método de projetos' nasceu para contrapor-se aos princípios e métodos da escola tradicional, que reforçava o sistema de produção em série (taylorista/fordista), cuja filosofia de trabalho concentrava o capital, o poder e o saber nas mãos de poucos" (Fleck, 2012, p. 02).

Considerando o aluno como um ser global, onde o afetivo, o cognitivo e o simbólico estão integrados, levando-a a sentir, pensar, agir e representar, inteirando o meio físico ao humano, caberá a escola criar espaços onde a troca de experiências, os significados, as ideias serão construídas e partilhadas.

A educação deve ser entendida e trabalhada de forma interdisciplinar, onde não se priorize somente uma área de conhecimento, mas sim, sua totalidade, tornando a atividade prazerosa, lógica e atrativa para a criança.

Outra vantagem que a Pedagogia de Projetos pode proporcionar aos educadores e alunos é a possibilidade de integrar as disciplinas do currículo ao assunto que está sendo trabalhado, o que implica em um leque de conhecimentos a ser abordado, desenvolvendo múltiplas aprendizagens (Martins \& Müller-Palomar, 2018, p. 40).

A aplicação do trabalho em sala de aula, é planejada em cima das dificuldades dos educandos, seja ela cognitiva, afetiva, motora, de socialização ou disciplinar. De forma proposital, elaboramos projetos da vida diária, ou seja, cotidiana de nossos educandos ou intencional, direcionados pelos procedimentos da Pedagogia de Projetos.

O tema é relevante pois pode acrescentar conhecimento a todos os profissionais que atuam em sala de aula. A escolha deste tema se deu com o intuito de analisar se os profissionais que atuam nas séries iniciais do ensino fundamental estão repensando suas estratégias e inovando em suas aulas, pois o saber não é um produto acabado, todos os dias algo novo vem surgindo e a pedagogia de projetos dá liberdade para que docentes e discentes aprendam juntos, fazendo com que as peculiaridades e competências do aluno sejam totalmente exploradas.

Hernández (1998) diz que há uma grande discussão sobre o tema e a definição não é como uma metodologia, a Pedagogia de Projetos é uma concepção de ensino, um novo olhar que desperta a compreensão sobre os conhecimentos dos alunos, isso acontece tanto dentro ou fora da escola, ajudando-o na sua construção do saber.

\section{Metodologia}

A abordagem sobre Pedagogia de Projetos transcorre por uma pesquisa bibliográfica embasada por documentos bibliográficos variados como livro, artigos de revistas e em sites especializados em educação. Buscamos discutir a importância da práxis educativa na Pedagogia de Projetos. O trabalho se compõe em uma pesquisa qualitativa exploratória de caráter teórico, bibliográfico e documental.

O trabalho em sala de aula com projetos rompe com a forma rígida de exposição de conteúdos pelo método tradicional, possibilitando, ao mesmo tempo, que estes conteúdos sejam inseridos num trabalho prático e dinâmico. Cabe ao docente possibilitar aos estudantes aspectos que instiguem a motivação necessária para concluir o desafio. Um dos pontos cruciais é desenvolver estratégias que encorajem o alcance do produto final (Negro-Dellacqua et al., 2020, p. 16).

As definições da Pedagogia de Projetos estão baseadas também no ensino interdisciplinar como forma de ensino, se relacionando com diferentes conteúdos e disciplinas e contextualizada no qual faz o aluno ter conexão entre os conhecimentos.

O referencial teórico transcorre pelas teorias de Hernandez (1998), Prado (2005), Bitte e Mouro (2021) e vários autores 
relacionados na referência bibliográfica, que pesquisaram sobre o tema revelando o valor e a contribuição das práticas inovadoras na educação, tão indispensável nos tempos atuais.

\section{Resultados e Discussão}

A Pedagogia de Projetos ganhou força no final do século passado e início deste século, quando há várias reflexões sociais sobre a definição dos conhecimentos escolares. Essa, apresenta-se como uma compreensão de atitudes pedagógicas e não meramente como uma metodologia educacional mais atrativa para os educandos. Tem um princípio ativo, integrador e com objetivo de minimizar a artificialidade da educação, escola e aproximá-la o mais possível dessa realidade e da vida do educando. Um trabalho capaz de fazer a escola ir além dos seus muros e criar pontos em meio aos conteúdos estudados e o meio físico e social, propiciando um entendimento melhor da historicidade dos tempos atuais e da formação conscientes de pessoas e de suas funções como construtores da história. Foram as percepções do norte-americano Dewey, um filósofo, que primeiro delineou a Pedagogia de Projetos.

John Dewey (1859-1952), filósofo, psicólogo e pedagogo liberal norte-americano, exerceu grande influência sobre toda a pedagogia contemporânea. Ele foi o defensor da Escola Ativa, que propunha a aprendizagem através pessoal do aluno. Sua filosofia da educação foi determinante para que a Escola Nova se propagasse por quase todo o mundo (Gadotti, 1993, p. 148).

A Pedagogia de Projeto é uma estratégia interdisciplinar que surge como uma probabilidade de organização e integração de todo trabalho pedagógico nas áreas de conhecimentos. O que é muito importante para o desenvolvimento da aprendizagem, e a descoberta do saber.

Aproxima-se da identidade dos alunos e favorece a construção da subjetividade, longe de um prisma paternalista, gerencial ou psicologista, o que implica considerar que a função da escola não e apenas ensinar conteúdos, nem vincular a instrução

coma aprendizagem. [...] O que torna necessária a proposta de um currículo que não seja uma representação do conhecimento fragmentada, distanciada dos problemas que os alunos vivem e necessitam responder em suas vidas, mas, sim, solução de continuidade (Hernandez, 1998, p. 61).

A proposta de projetos se propõe a transformar as atitudes dos alunos durante o ensino. $\mathrm{O}$ aluno deve converter-se em um ser ativo que concebe, prepara e executa o próprio trabalho. A tarefa do professor consiste em dirigi-lo, sugerir-lhe ideias, e auxiliá-lo quando necessário, tem um princípio ativo, integrador e o objetivo é minimizar a artificialidade da escola e aproximála o mais possível da realidade e da vida do aluno. Fazendo a escola ir além dos seus muros e criar pontos entre os conteúdos estudados e o meio físico e social, propiciando melhor compreensão da historicidade do nosso tempo e a formação de pessoas conscientes de seu papel como construtores de história.

[...] o professor precisa acompanhar o processo de aprendizagem do aluno, ou seja, entender seu caminho, seu universo cognitivo e afetivo, bem como sua cultura, história e contexto de vida. Além disso, é fundamental que o professor tenha clareza da sua intencionalidade pedagógica para saber intervir no processo de aprendizagem do aluno, garantindo que os conceitos utilizados, intuitivamente ou não, na realização do projeto sejam compreendidos, sistematizados e formalizados pelo aluno (Prado, 2005, p. 13).

Na proposta de projetos o professor é alguém que assume a coordenação do processo sem que isso signifique a imposição de única lógica: a sua. O aluno é sujeito cultural, que usa sua experiência e conhecimento para resolver problemas colocados pelo projeto. Os conteúdos das disciplinas são vistos como instrumentos necessários para a compreensão e intervenção da realidade, estudados dentro de um contexto que lhe dá sentido, passando a ser meios para ampliar a formação dos alunos e 
sua interação com a realidade crítica e dinâmica.

Podemos também evidenciar que o educador é fundamental no processo de aprendizagem, sendo necessário superar os preceitos ou dificuldades que os impossibilitam de conduzir e transformar a sala de aula como fomentadora de ideias e de inovação. O exercício do educador é um processo diário que exige aperfeiçoamento sobre o conhecimento com a prática (Santos et al., 2020, p. 24).

O projeto tem uma atitude intencional, uma estratégia de trabalho, uma abundância de tarefas que tendem a uma crescente participação independente e social dos educandos nas atividades cultivadas, por ele e pelo grupo, sob a liderança do docente. Entretanto, um projeto colocar-se como uma sugestão de intervir pedagogicamente, dando celeridade ao ensino e aprendendo um sentido novo, aflorando problemáticas no ensino aprendizagem. Um projeto gera circunstâncias de aprendizagem diversificadas e gerais. Favorecendo a autonomia e a autodisciplina, de ocorrências no qual surgiram em sala de aula, propiciando ao educando, a prática social do seu compromisso, transformado em sujeito do seu conhecimento próprio. Prado (2001) evidência a oportunidade de o aluno redescrever a aprendizagem adquirida, estabelecendo uma ponte nos conhecimentos significativos. Dessa maneira, o aluno ressignifica os conceitos e as estratégias utilizadas na investigação que iniciou o projeto ampliando o seu ensino aprendizagem.

"Na pedagogia de projetos, o aluno aprende no processo de produzir, levantar dúvidas, pesquisar e criar relações que incentivam novas buscas, descobertas, compreensões e reconstruções de conhecimento" (Prado, 2005, p. 13).

O mais interessante é que o educando tem muitas dificuldades durante o processo, em ter iniciativa e autonomia, momentaneamente, sem a experiência de ter oportunidades de decisão, escolha, de falar o que pensa, formulando opiniões e críticas.

A função metodológica da Pedagogia do projeto é fazer transformações no ensino aprendizagem com uma metodologia ativa e significativa, para o educando, incluindo a educação em um projeto participativo e dinâmico, sem atribuir conteúdo programáticos autoritariamente. Portanto, o educando faz uma investigação e adquire informações, estabelece proposições, comenta informações, avalia, convertendo em assuntos iniciais, para as inovações cognitivas.

A pedagogia baseada em projetos visa desenvolver uma aprendizagem significativa no aluno. A aprendizagem significativa se caracteriza pela interação entre conhecimentos prévios e conhecimentos novos, e que essa interação é não-literal e não-arbitrária. Nesse processo, os novos conhecimentos adquirem significado para o sujeito e os conhecimentos prévios adquirem novos significados ou maior estabilidade cognitiva (Moreira, 2018, p. 02).

Com um olhar aberto, aos conteúdos das disciplinas, numa visão e perspectiva, os conteúdos, antes analisados como teóricos e abstratos, abandonam em si mesmos esse fim para serem meios, processos que ampliam a formação dos educandos inteirando-os com a realidade, com sua criticidade e eficácia. Existe a quebra com os aspectos da "neutralidade", ante conteúdos disciplinares que recebem significados múltiplos, através das vivências, experiências sociais dos educandos, inseridos nos projetos.

A Pedagogia de Projetos apresenta três momentos distintos, porém complementares:

\section{A - A Etapa da Problematização:}

É o olhar, a observação inicial, o período detonador de todo o projeto, no qual, os educandos expressarão suas crenças, necessidades, confianças e ideias, informações diante a problemática em questão. É a partir destas questões que o educador deverá ter habilidade para conduzir os educandos a apresentarem suas hipóteses problematizando o cotidiano, tendo como base 
o referencial dos Parâmetros Curriculares.

Assim, nessa fase da problematização, o professor, ao diagnosticar os saberes prévios dos alunos, identifica o que eles já sabem e o que desconhecem sobre o tema que lhes foi proposto. As inquietações dos alunos, levantadas nessa etapa, orientam a organização do projeto (Bitte \& Mouro, 2021, p. 1301-1302).

\section{B - Desenvolvimento:}

É o momento dos educandos, com a coordenação e mediação do educador, estarem apresentando e debatendo as estratégias que poderão ser adotadas para a solução das questões colhidas na etapa de problematização. As estratégias a serem criadas devem propiciar aos educandos a defrontação com as situações que os obriguem a checar com diversos pontos de vista, reavaliando suas hipóteses, acrescentando novas estratégias. É necessário que o projeto complete propostas que determinem as saídas dos espaços escolares, a organização de grupos pequenos e grandes, a ida a exposições, empresas, parques, dentre as diferentes ações. Os educandos, mediados pelos educadores, utilizam diversos conhecimentos adquiridos do tema ao defrontarem com as inquietações e conflitos, que os induzirão ao desequilíbrio, a instabilidade de diversas hipóteses iniciais, estabelecendo novas relações num contínuo permanente. E no meio social, na inter-relação entre ambos que surgem situações propícias à problematização e o estímulo para o exercício de possibilidades de solução, tendo em vista que cada sujeito opera da maneira diferente e estabelece caminhos e hipóteses substancialmente diversas, na constituição do conhecimento, ainda que trabalhem com o mesmo processo.

"Nessa fase, o professor deve propor, implementar estratégias e metodologias que instiguem o discente a analisar, explicar, perceber mudanças, permanências, rupturas e continuidades, revendo hipóteses, criando problemas e abordagens" (Bitte \& Mouro, 2021, p. 1302).

A valorização desta estratégia que extrapola os espaços e tempos escolares dará oportunidade real ao educando de estar construindo, refletindo, reconstruindo sobre o objetivo da aprendizagem e com isso ampliando os limites de participação nas aulas.

\section{C - A Síntese:}

Este momento não deve ser entendido como etapa que encerrará o trabalho, mas como momento de síntese, de novas hipóteses que deverão ser, também, questionadas. Em toda essa metodologia, valores e ideias primárias passam cotidianamente a se tornarem obsoletas e diferentes, ao próprio tempo complexas e contínuas. As inovações no ensino aprendizagem, fazem parte do conhecimento real do educando e servirão de conhecimento, precedente, para os outros casos de aprendizagem.

"A fase da síntese se caracteriza pela mescla da problematização, do desenvolvimento, quando hipóteses e convicções iniciais são revistas" (Bitte \& Mouro, 2021, p. 1302).

\section{Considerações Finais}

A finalidade de estudar é decorrente da motivação de resolver problemas que são apresentados. Assim, os educandos sabem o quê e para que estão aprendendo. Um projeto gera conjunturas na aprendizagem, reais e simultaneamente diversificadas. Possibilita, também, aos educandos, decidirem, opinarem e, debaterem, construindo sua autonomia e se comprometendo socialmente.

"O fato de a pedagogia de projetos não ser um método para ser aplicado no contexto da escola dá ao professor uma liberdade de ação que habitualmente não acontece no seu cotidiano escolar" (Prado, 2005, p. 16). 
Uma proposta interdisciplinar frente ao conhecimento demanda uma atitude educacional globalizante, na qual as habilidades e competências escolares e as questões sociais se completem, rompendo-se assim com a dicotomia ainda existente entre aprendizagem na escola e na vida.

A pedagogia de projetos deve permitir que o aluno aprenda-fazendo e reconheça a própria autoria naquilo que produz por meio de questões de investigação que lhe impulsionam a contextualizar conceitos já conhecidos e descobrir outros que emergem durante o desenvolvimento do projeto (Prado, 2005, p. 15).

Não se limitando a uma visão utilitarista da educação, mas buscando dar um sentido prático aos conhecimentos escolares, é importante para escola também, fazer parte da investigação de alternativas possíveis de soluções às situações colocadas pelo cotidiano.

Daí a importância do desenvolvimento de projetos articulados que envolvam a co-autoria dos vários protagonistas do processo educacional. $\mathrm{O}$ fato de um projeto de gestão escolar estar articulado com o projeto de sala de aula do professor, que por sua vez visa propiciar o desenvolvimento de projetos em torno de uma problemática de interesse de um grupo de alunos, integrando o computador, materiais da biblioteca e a televisão, torna-se fundamental para o processo de reconstrução de uma nova escola (Prado, 2005, p. 14).

Nessa conjuntura, a Pedagogia de Projeto surge como alternativa possível da estratégia na abordagem do conhecimento, sabendo que o desenvolvimento, suscite a adoção de outras estratégias como laboratório de ensino aprendizagem, parceria, o trabalho diversificado, pesquisa e quantas outras se mostrem necessárias no momento, vindo a materializar no ambiente escolar um processo educacional interdisciplinar aberto a possíveis intervenções curriculares, seja por iniciativa dos educandos, dos educadores ou indagações sociais emergentes que, no entender do grupo (educandos, educadores, pais), demandem uma ação educacional mais sistematizada.

[...] a pedagogia de projetos é vista pelo seu caráter de potencializar a interdisciplinaridade. Isto de fato pode ocorrer, pois o trabalho com projetos permite romper com as fronteiras disciplinares, favorecendo o estabelecimento de elos entre as diferentes áreas de conhecimento numa situação contextualizada da aprendizagem (Guedes et al., 2017, p. 249).

\section{Referências}

Bitte, R. C. F., \& Mouro, F. M. G. (2021). Pedagogia de projetos no ensino de história. Revista Interinstitucional Artes de Educar, 7 (2), $1300-1312$. https://www.e-publicacoes.uerj.br/index.php/riae/article/view/63469/39858.

Fleck, M. L. S. (2012). Pedagogia de Projetos. http://200.156.70.12/sme/cursos/EAD/EA05/arqs/PedagogiaDeProjetos-Genese.pdf.

Gadotti, M (1993). História das Ideias Pedagógicas. Ática.

Guedes, J. D.; Souza, A. S.; Sidrim, F. M. L., \& Lima, Q. F. O. (2017). Pedagogia de projetos: uma ferramenta para a aprendizagem. Revista Multidisciplinar e de Psicologia, 10 (33), Supl. 2. 237-256.

Hernadez, F (1998). Transgressão e mudança na educação: projetos de trabalho. ArtMed.

Hernandes, F., \& Ventura, M. (2017). A Organização do Currículo por Projetos de trabalho (5a ed.). Artes Médicas.

Leite, D. A. (1996). Pedagogia de projetos: intervenção no presente. Presença Pedagógica, 2 (8), 25-33. https://docplayer.com.br/15523901-Pedagogia-deprojetos-intervencao-no-presente-lucia-helena-alvarez-leite-1-os-projetos-de-trabalho-o-espaco-escolar-e-a-formacao-dos-alunos.html.

Lima, A. O. (2010). Uso da metodologia de projetos visando uma aprendizagem significativa de física. Um estudo contextualizado das propriedades do solo. Dissertação (Mestrado em Ciências) - Universidade Federal Rural do Rio de Janeiro, Seropédica, Rio de Janeiro.

Martins, F. F., \& Müller-Palomar, M. T. (2018). Pedagogia de projetos: uma estratégia metodológica no processo de ensino aprendizagem. Revista Eletrônica Facp, (13), 26-44. http://facp.com.br/revista/index.php/reFACP/article/viewFile/60/pdf.

Moreira, MA (2012). O que é afinal aprendizagem significativa? http://moreira.if.ufrgs.br/oqueeafinal.pdf. 
Research, Society and Development, v. 11, n. 2, e38911221567, 2022

(CC BY 4.0) | ISSN 2525-3409 | DOI: http://dx.doi.org/10.33448/rsd-v11i2.21567

Negro-Dellacqua, M.; Sousa, I. F.; Alexandre, C. S.; Machado, C. F. B.; Weingärtner, B. L.; Borges, M. C. S. \& Silva, L. E. (2020). Utilização da Aprendizagem Baseada em Projetos no ensino de Biologia Celular e Molecular: relato de experiência no curso de Fisioterapia. Pesquisa, Sociedade e Desenvolvimento, 9 (8), e417985579. https://doi.org/10.33448/rsd-v9i8.5579.

Nogueira, N. R. (2008). Pedagogia de Projetos. Etapas, papéis e atores (4a ed.). Érica.

Pereira, T. S., \& Probst, M. (2020). Pedagogia de projetos: um estudo sobre a construção do conhecimento e da autonomia dos estudantes. Revista da Educação, $20(1), 115-133$

Prado, M. E. B. B. (2001). Articulando saberes e transformando a prática. Boletim do Salto para o Futuro. Série Tecnologia e Currículo, TV Escola. Secretaria de Educação a Distância. Ministério da Educação.

Prado, M. E. B. B. (2005). Pedagogia de projetos: fundamentos e implicações. In: Almeida, MEB \& Moran, JM (Org.). Integração das tecnologias na educação. Ministério da Educação/SEED/TV Escola/Salto para o Futuro, 12-17.

Santos, E. H.; Nakamoto, P. T., \& Lima, G. G.. (2020). Revisão sistemática da literatura em aprendizagem baseada em projetos do ensino médio. Pesquisa, Sociedade e Desenvolvimento, 9 (9), e386996425. https://doi.org/10.33448/rsd-v9i9.6425.

Senac, D N. (2015). Projeto Integrador. Senac.

Silva, W. R. (2011). Construção da Interdisciplinaridade no Espaço Complexo de Ensino e Pesquisa. Cadernos de Pesquisa, 41 (143), 582-605. http://publicacoes.fcc.org.br/ojs/index.php/cp/article/view/104.

Ventura, P. C. S. (2002). Por uma Pedagogia de Projetos: Uma Síntese Introdutória. Educação Tecnológica, 7 (1), 36-41. https://periodicos.cefetmg.br/index.php/revista-et/article/view/31/26. 